\title{
ARTIKELEN
}

\section{Minderjarige verdachten in een politiecel}

\author{
Een rechtsvergelijkend onderzoek naar de oplegging van \\ voorlopige vrijheidsbenemende maatregelen bij jeugdigen in \\ Nederland en België in theorie en praktijk ${ }^{*}$
}

Viviane Wennekes

\section{Inleiding}

Helaas is het geen uitzondering: jeugdigen die illegaal vuurwerk kopen of een vechtpartij beginnen. Om onderzoek te kunnen doen naar het gepleegde delict kan de politie een minderjarige verdachte oproepen voor een verhoor op het bureau. Het doel hiervan is om meer duidelijkheid te verkrijgen over de zaak. Een verdachte, ook een minderjarige, kan in afwachting van het strafproces in voorarrest worden geplaatst. Dit kan nodig zijn om het opsporingsonderzoek goed te laten verlopen of om de maatschappij te beschermen. In verschillende internationale en Europese verdragen en richtlijnen zijn waarborgen neergelegd die van belang zijn voor de regelgeving betreffende de voorlopige vrijheidsbeneming van minderjarige verdachten. ${ }^{1}$ Uit het Internationaal Verdrag inzake de Rechten van het Kind (IVRK) volgt dat voorlopige vrijheidsbenemende maatregelen slechts mogen worden toegepast als uiterste maatregel en voor de kortst mogelijke duur (art. 37, aanhef en onder b, IVRK). Ook is de Richtlijn 2016/800/EU 2 belangrijk, die op 11 juni 2019 door de lidstaten van de Europese Unie dient te zijn geïmplementeerd. Hieruit volgt onder andere dat jeugdigen recht hebben op consultatiebijstand voorafgaande aan en tijdens het politieverhoor (art. 6 Richtlijn 2016/800/EU). Belangrijk is het uitgangspunt dat de vrijheidsbeneming in elke fase van de procedure zo kort dient te duren als passend is. Vrijheidsbeneming blijft een uiterste maatregel, zeker in het geval de jeugdige nog niet is veroordeeld (art. 10 Richtlijn 2016/800/EU). Daarnaast dienen lidstaten ervoor te zorgen dat alternatieve maatregelen worden gebruikt waar mogelijk (art. 11 Richtlijn 2016/800/EU). Indien alsnog wordt gekozen voor het opleggen van een vrijheidsbenemende maatregel, moeten lidstaten zorgen voor een specifieke behandeling bij minderjarige verdachten.

* $\quad$ Mr. V.C. Wennekes heeft in 2019 de master Double Degree Programme Toga aan de Maas aan de Erasmus Universiteit Rotterdam afgerond en is momenteel werkzaam als juridisch medewerker bij de Rechtbank Rotterdam.

1 Y.N. van den Brink e.a., Voorlopige hechtenis van jeugdigen in uitvoering. Een exploratief kwantitatief onderzoek naar rechterlijke beslissingen en populatiekenmerken, Den Haag: WODC 2017, p. 14.

2 Richtlijn (EU) 2016/800 van het Europees Parlement en de Raad van 11 mei 2016 betreffende procedurele waarborgen voor kinderen die verdachte of beklaagde zijn in een strafprocedure. 
Zowel in Nederland als in België bestaan bijzondere regelingen voor minderjarigen die in strijd hebben gehandeld met een wettelijke bepaling. In tegenstelling tot Nederland heeft België geen jeugdstrafrecht, maar kent het het jeugdbeschermingsrecht. Ondanks de verschillende invalshoeken moeten beide landen zich aan dezelfde internationale rechtswaarborgen houden, met name met betrekking tot de bijzondere rechtspositie van jeugdigen tijdens het opleggen van voorlopige vrijheidsbenemende maatregelen. De zogenoemde voorlopige vrijheidsbenemende maatregel begint in Nederland op het moment dat de verdachte in een politiecel wordt geplaatst. De maatregel eindigt op het moment dat de voorlopige hechtenis wordt beëindigd, ofwel door het uitspreken van een vonnis door de rechter, ofwel door de rechter-commissaris. Ook in België begint de voorlopige vrijheidsbenemende maatregel als de verdachte in een politiecel wordt geplaatst. Deze eindigt bij beëindiging van de voorlopige vrijheidsbenemende maatregel in een gesloten inrichting.

Het is de vraag of de regelgeving en praktijk van zowel Nederland als België al voldoen aan de bepalingen die zijn opgenomen in de Richtlijn 2016/800/EU of dat er nog enige aanpassing noodzakelijk is. Om deze reden zal in deze bijdrage worden onderzocht in hoeverre de regelgeving en praktijk van Nederland en België de rechten en belangen van jeugdige verdachten waarborgen wat betreft het opleggen van voorlopige vrijheidsbenemende maatregelen. In paragraaf 2 zullen verschillende onderdelen van de voorlopige vrijheidsbenemende maatregelen op het gebied van regelgeving en praktijk worden getoetst aan de Europese normen, afkomstig van de richtlijn. Hierbij zal onder andere worden gekeken naar het verblijf in een politiecel, de alternatieve wijzen voor tenuitvoerlegging en de schorsing of het uitstellen van de voorlopige vrijheidsbenemende maatregelen. In paragraaf 3 zal worden afgesloten met een antwoord op de onderzoeksvraag en het geven van enkele aanbevelingen.

\section{Voorlopige vrijheidsbenemende maatregelen; de Europese norm versus de regelgeving en praktijk van Nederland en België}

\subsection{Het verblijf in een politiecel}

In artikel 10 van de Richtlijn 2016/800/EU is neergelegd dat lidstaten ervoor dienen te zorgen dat de vrijheidsbeneming van minderjarigen tijdens elke fase zo kort duurt als passend is. Er moet rekening worden gehouden met de leeftijd en de individuele situatie van het kind en met de unieke omstandigheden van de zaak in kwestie. Daarnaast dient vrijheidsbeneming te worden opgelegd als uiterste maatregel en onderworpen te zijn aan periodieke rechterlijke toetsing. In artikel 12 van de Richtlijn 2016/800/EU staat de bepaling dat lidstaten ervoor dienen te zorgen dat minderjarigen gescheiden van volwassenen worden vastgehouden.

Volgens de wet mag een minderjarige verdachte in Nederland 3 dagen en 18 uur worden opgehouden in een politiecel voordat de jeugdige voor de rechter-commissaris - de kinderrechter - moet verschijnen (art. 59a lid 1 Wetboek van Straf- 
vordering (Sv)). In totaal kan de jeugdige 6 dagen en 18 uur worden opgehouden voor onderzoek - de fase van inverzekeringstelling - in een politiecel. ${ }^{3}$ Ingevolge artikel 15 Beginselenwet justitiële jeugdinrichtingen (Bjj) kan een jeugdige maximaal 10 dagen in een politiecel verblijven indien hij of zij de leeftijd van 16 jaar heeft bereikt en er geen plaats beschikbaar is in een justitiële jeugdinrichting. Voor jeugdigen onder de 16 jaar geldt een maximale periode van 3 dagen en mag het verblijf in een politiecel voor de duur van deze periode alleen in afwachting van het regelen van vervoer naar de plaats in de justitiële jeugdinrichting. In België bestaan geen speciale regels voor jeugdigen tijdens de voorlopige vrijheidsbeneming in een politiecel. Het Hof van Cassatie heeft bepaald dat jeugdigen - net zoals volwassenen - binnen 24 uur voor de rechter moeten verschijnen. Indien het de rechter niet lukt om binnen 24 uur een voorlopige vrijheidsbenemende maatregel op te leggen, dient de jeugdige in vrijheid te worden gesteld. ${ }^{4}$

Hoe verhoudt de praktijk van Nederland en België op het gebied van de voorlopige vrijheidsbeneming in politiecellen zich met de regelgeving van beide landen? In 2011 heeft Defence for Children een onderzoek ingesteld naar de rechtspositie van minderjarige verdachten in politiecellen in Nederland. ${ }^{5}$ Uit deze cijfers blijkt dat het aantal politieverhoren is afgenomen, maar dat de inverzekeringstelling in de periode tussen 2008 en 2011 fors is toegenomen. Onduidelijk blijft hoeveel jeugdigen tegenwoordig in een politiecel dienen te overnachten. ${ }^{6}$ Daarnaast is niet bekend hoelang jeugdige verdachten na 2015 in een politiecel verblijven. In de periode 2012-2014 is het aantal jeugdige verdachten dat in de nacht in verzekering is gesteld gedaald, terwijl dit aantal in 2015 weer is gestegen. ${ }^{7}$ In België worden geen statistieken bijgehouden over de leeftijd van verdachten in een politiecel, waardoor niet bekend is hoeveel jeugdigen in een politiecel overnachten. ${ }^{8}$ Het Kinderrechtencomité heeft al verschillende keren gewezen op het feit dat België in zijn algeheel geen voldoende en recente dataverzameling kent. ${ }^{9}$

Uit het rapport Een nacht in de cel $(2015)^{10}$ blijkt dat de regeling waarin is vastgelegd dat een jeugdige niet mag worden verhoord zonder de consultatie en aanwezigheid van een advocaat tijdens het verhoor, zorgt voor langere wachttij-

3 Ingevolge art. 56a lid 2 in combinatie met art. 58 lid 2 Sv.

4 Cassatie 15 mei 2002, A.C. 2002, nr. 296, p. 1291-1292.

5 M. Berger \& C. van der Kroon, Een 'paar nachtjes' in de cel. Het VN-Kinderrechtenverdrag en het voorarrest van minderjarigen in politiecellen, Leiden: DCI 2011, p. 9.

6 Berger \& Van der Kroon 2011, p. 19-23; zie voor de cijfers van 2007 T. Liefaard, Deprivation of Liberty of children in Light of International Human Rights and Standards (diss.), Antwerpen: Intersentia 2008, p. 396.

7 A. Bolscher e.a., Advies Kinderrechtenmonitor 2016. In opdracht van De Kinderombudsman, Universiteit Leiden 2016, p. 88.

8 S. Detrick e.a., Violence against children in conflict with the law. A study on Indicators and Data Collection in Belgium, England and Wales, France and the Netherlands, Amsterdam: DCI 2008, p. 38.

9 Kinderrechtencomité, Concluding Observations of the Committee on the Rights of the Child: Belgium (CRC/C/BEL/CO/3-4), 18 juni 2010, onder 8, 21, 22, 32 en 43.

10 De Kinderombudsman, Rapport: 'een nacht in de cel'. Een onderzoek naar aanleiding van een klacht over het Openbaar Ministerie te Amsterdam en aanverwante signalen, 30 maart 2015, KOM007/2015. 
den op het politiebureau. Dat er niet altijd tijdig een advocaat beschikbaar is, met name in de avonduren, lijkt in Nederland een grote oorzaak te zijn van een overnachting in een politiecel. ${ }^{11}$ In België kent men soortgelijke problemen wat betreft de duur van het verblijf in een politiecel door het wachten op een advocaat. Volgens de Kindercoalitie zijn de wachttijden in de politiecel voor jeugdige verdachten 'angstwekkend', waarbij de cellen ook niet zijn aangepast aan de jeugdige leeftijd van verdachten. ${ }^{12}$ Defence for Children geeft de aanbeveling aan advocaten in België om niet te laat bij de jeugdige te verschijnen voor het verhoor in verband met de gevolgen die de afwezigheid van de advocaat kan hebben voor de jeugdige. ${ }^{13}$ Uit het rapport Achter slot en grendel ${ }^{14}$ komt met name naar voren dat in Nederland onvoldoende rekening is gehouden met de leeftijd van de jeugdige verdachte, terwijl rekening houden met de jeugdige leeftijd en daarmee de kindvriendelijke omstandigheden een belangrijk uitgangspunt is van artikel 37 IVRK. Opmerking verdient dat de kindvriendelijke richtlijnen voor het verblijf van een jeugdige in een politiecel ten tijde van dit onderzoek nog niet in werking waren getreden. ${ }^{15}$ België kent een dergelijke regeling, waarbij een aparte afdeling voor minderjarigen op een politiebureau moet bestaan, ook niet, maar in de praktijk kennen grotere korpsen een dergelijke afdeling al wel. ${ }^{16}$

\subsection{Alternatieve wijzen voor de tenuitvoerlegging}

Uit paragraaf 46 en artikel 11 van de Richtlijn 2016/800 EU kan worden geconcludeerd dat alternatieven voor de voorlopige vrijheidsbenemende maatregel de voorkeur verdienen (in lijn met art. 37 onder b IVRK). Lidstaten dienen waar mogelijk gebruik te maken van alternatieve maatregelen. Hierbij kan onder andere worden gedacht aan een locatie- of contactverbod, het verplicht laten volgen van onderwijsprogramma's of het volgen van een behandeling.

In Nederland kennen we twee alternatieve vormen van tenuitvoerlegging in een justitiële jeugdinrichting: de mogelijkheid om de voorlopige hechtenis op een andere plaats ten uitvoer te leggen en de nachtdetentie (art. 493 lid 3 Sv). België kent vier alternatieve wijzen voor de tenuitvoerlegging van de voorlopige vrijheidsbenemende maatregel in een gesloten inrichting. Ten eerste kan de jeugdige worden geplaatst bij de ouders onder toezicht van de sociale dienst zonder voorwaarden (art. $37 \S 22^{\circ}$ Jeugdbeschermingswet (JBW)). Ten tweede kan de jeugdige worden geplaatst bij de ouders onder toezicht van de sociale dienst met voorwaarden (art. $37 \S 22^{\circ} \mathrm{JBW}$ ). Ten derde kan de jeugdige worden geplaatst bij een betrouwbaar geacht persoon (familielid) of bij een derde, neergelegd in artikel 37

12 Kinderrechtencoalitie Vlaanderen, Alternatief rapport van de NGO's. Over de naleving en de toepassing van het Verdrag inzake de Rechten van het Kind in België, Brussel: Hayez 2018, p. 128-129.

13 M. Braun e.a., My lawyer, my rights. De rol van de jeugdadvocaat in de jeugdbeschermings- en strafrechtelijke procedures in België, België: DCI 2016-2018, p. 81.

14 De Kinderombudsman, 'Achter slot en grendel'. Een onderzoek naar de inverzekeringstelling van een minderjarige, 1 september 2016, KOM2016/016.

15 De Kinderombudsman 2016, p. 21.

16 Berger \& Van der Kroon 2011, p. 115. 
$\S 27^{\circ} \mathrm{JBW}$. Tot slot kan de jeugdrechter in België de jeugdige (mits 12 jaar of ouder) in een open instelling plaatsen, waarbij hij of zij onder toezicht staat van de sociale dienst (art. $37 \S 28^{\circ} \mathrm{JBW}$ ). De vereisten voor het opleggen van de maatregel plaatsing in een open opvoedingsafdeling in een gemeenschapsinstelling zijn neergelegd in artikel 37 2quater JBW.

Zoals hiervoor is beschreven, bestaan in Nederland twee alternatieve wijzen van tenuitvoerlegging in de fase van de voorlopige hechtenis: de mogelijkheid om de voorlopige hechtenis op een andere plaats ten uitvoer te leggen - bijvoorbeeld thuisdetentie - en de nachtdetentie (neergelegd in art. 493 lid 3 Sv). ${ }^{17}$ In 2017 is door het Wetenschappelijk Onderzoek- en Documentatiecentrum (WODC) onderzoek gedaan naar het opleggen van de voorlopige hechtenis bij jeugdigen in de praktijk. In dit onderzoek is van de 99 jeugdige verdachten maar bij één jeugdige nachtdetentie opgelegd als alternatieve tenuitvoerlegging van inbewaringstelling. Brink e.a. concluderen uit dit onderzoek dat nachtdetentie in de praktijk nauwelijks wordt toegepast. Ondanks dat nachtdetentie verankerd is in de wet - en wel als positief wordt ervaren - blijft de toepassing van nachtdetentie vrijwel achterwege. Dit komt ook door praktische problemen, bijvoorbeeld als de afstand tussen de gevangenis en de verdachte te groot is. In het geval van alternatieve tenuitvoerlegging van gevangenhouding is de raadkamer in vier gevallen (van de 77) overgegaan tot nachtdetentie. De alternatieve tenuitvoerlegging bij verlenging van de gevangenhouding in de vorm van nachtdetentie is tweemaal opgelegd. In ditzelfde onderzoek van het WODC is onderzocht in hoeverre gebruik wordt gemaakt van de mogelijkheid om de voorlopige hechtenis op een andere plaats ten uitvoer te leggen. Van de 99 jeugdige verdachten werd bij één jeugdige thuisdetentie opgelegd als alternatieve wijze van tenuitvoerlegging van inbewaringstelling. Ook wat betreft de tenuitvoerlegging op een andere plaats - in dit geval thuisdetentie - kan volgens Van den Brink e.a. worden geconcludeerd dat hier in de praktijk vrijwel geen gebruik van wordt gemaakt. In het geval van alternatieve tenuitvoerlegging van gevangenhouding is door de raadkamer eenmaal thuisdetentie opgelegd en bij verlenging van gevangenhouding tweemaal. ${ }^{18}$

België kent verschillende wijzen waarop de voorlopige vrijheidsbenemende maatregel op een andere manier ten uitvoer wordt gelegd. In het onderzoek van Gilbert e.a. uit 2012 is onderzocht hoe vaak een voorlopige maatregel in België in de praktijk wordt opgelegd. ${ }^{19}$ Als deze gegevens zouden worden vergeleken met het onderzoek van het WODC uit 2017 is een aantal opmerkingen relevant voor de praktijk van het opleggen van alternatieven betreffende de voorlopige vrijheidsbenemende maatregel. Waar in Nederland slechts in $2 \%$ van de gevallen van bevel tot bewaring over wordt gegaan tot een alternatieve tenuitvoerlegging, blijkt in België veel sneller te worden gekozen om de jeugdige niet in een inrichting te

17 RSJ, Voorlopige hechtenis - maar dan anders. Verkenning van alternatieven in het kader van schorsing en tenuitvoerlegging, 4 juli 2011, p. 15.

18 Van den Brink e.a. 2017, p. 64, 80 en 90.

19 E. Gilbert e.a., Onderzoek naar de beslissingen van jeugdrechters/jeugdrechtbanken in MOF-zaken (eindrapport), september 2012, p. 46. 
plaatsen. Aan de andere kant wordt in Nederland in de fase van bevel tot bewaring sneller overgegaan tot geen bevel inbewaringstelling (in 13\% van de gevallen), in tegenstelling tot slechts $4 \%$ in België. ${ }^{20}$ Bij het bevel tot gevangenhouding is slechts in $6 \%$ van de gevallen overgegaan tot een alternatieve wijze van tenuitvoerleggen. ${ }^{21}$ Opmerking verdient dat in beide gevallen waarin in Nederland vrij weinig gebruik wordt gemaakt van de alternatieve wijze van tenuitvoerlegging, wel veelvuldig gebruik wordt gemaakt van de schorsing van de tenuitvoerlegging onder voorwaarden. In praktijk lijkt deze vorm met voorwaarden veel op de modaliteiten in België als alternatieve voorlopige maatregelen.

\subsection{De tenuitvoerlegging schorsen (Nederland) of uitstellen (België)}

Jeugdigen in vrijheidsbeneming verkeren in een bijzonder kwetsbare positie, met name gelet op de mogelijke risico's voor hun mentale, lichamelijke en sociale ontwikkeling bij vrijheidsbeneming. Om deze reden is in paragraaf 45 en artikel 10 van de Richtlijn 2016/800/EU neergelegd dat lidstaten uitdrukkelijk moeten streven naar het voorkomen van vrijheidsbeneming bij jeugdigen die nog niet zijn veroordeeld. Deze waarborg sluit aan bij de aanbeveling van het VN Kinderrechtencomité om lidstaten te laten verzekeren dat een kind zo snel mogelijk in vrijheid wordt gesteld, indien noodzakelijk onder voorwaarden. ${ }^{22}$

In het jeugdstrafrecht in Nederland wordt veelvuldig gebruikgemaakt van schorsing van tenuitvoerlegging van de voorlopige hechtenis (art. $493 \mathrm{~Sv}$ ). ${ }^{23}$ De kinderrechter dient ambtshalve na te gaan of het bevel kan worden geschorst. Tijdens de schorsing kunnen algemene voorwaarden worden opgelegd (art. 493 lid 6 Sv in combinatie met art. $80 \mathrm{~Sv}$ ). Daarnaast kunnen bijzondere voorwaarden worden opgelegd, welke zijn neergelegd bij algemene maatregel van bestuur. ${ }^{24}$ Bijzondere voorwaarden kunnen alleen aan de schorsing worden verbonden indien de rechter advies heeft ingewonnen van de Raad voor de Kinderbescherming en de jeugdige met deze voorwaarden instemt. In het jeugdbeschermingsrecht in België kan de jeugdrechter de uitvoering van de plaatsingsmaatregel uitstellen voor een termijn van zes maanden (art. $37 \S 2$ JBW). De jeugdige moet hiervoor wel aan de voorwaarde voldoen dat hij of zij een prestatie van opvoedkundige aard van algemeen nut van ten hoogste 150 uur uitvoert. Door de tenuitvoerlegging te schorsen of uit te stellen voldoen Nederland en België qua wettelijke regelgeving aan deze waarborg.

Uit het onderzoek van het WODC uit 2017 blijkt dat de rechter-commissaris in Nederland in $55 \%$ van de gevallen overgaat tot schorsing van de tenuitvoerlegging bij het bevel inbewaringstelling. ${ }^{25}$ Wat betreft de schorsing van de tenuitvoerlegging van de gevangenhouding is de raadkamer in een kwart van de 
gevallen overgegaan tot schorsing. ${ }^{26}$ De raadkamer is bij de verlenging gevangenhouding in 19 van de 54 zaken overgegaan tot schorsing, allemaal inclusief bijzondere voorwaarden. Uit dit onderzoek lijkt te volgen dat de raadkamer wordt beïnvloed door het advies van de Raad voor de Kinderbescherming en nooit - in dit onderzoek - ambtshalve overgaat tot schorsing. ${ }^{27}$ In België is in 2012 door Gilbert e.a. onderzoek gedaan naar de modaliteit van plaatsing met uitstel. In België wordt vrijwel geen gebruik gemaakt van plaatsing met uitstel. In de periode van 2001 tot 2012 is de modaliteit acht maal opgelegd aan de Franstalige kant en geen enkele keer aan de Nederlandstalige kant. Als oorzaak hiervoor werd door jeugdrechters omschreven dat plaatsing met uitstel wel is vastgelegd in de wet, maar in de praktijk praktische problemen kent. Met name het scenario dat de jeugdige zich niet aan de voorwaarden zou houden tijdens het uitstel en daarna geplaatst zou moeten worden in een inrichting, blijkt niet altijd mogelijk wegens gebrek aan plaats. De maatregel blijkt in praktijk vooral te worden opgelegd om de jeugdige af te schrikken en niet - zoals in Nederland met name het geval is om vroegtijdig interventies te kunnen faciliteren. ${ }^{28}$

\section{Conclusie}

Zowel Nederland als België kent bijzondere regelgeving als het gaat om jeugdige verdachten. De wettelijke regelingen van Nederland en België lijken op het eerste oog grotendeels te voldoen aan de internationale waarborgen betreffende het opleggen van de voorlopige vrijheidsbenemende maatregelen. Met name in de eerste fase van de voorlopige vrijheidsbenemende maatregelen - het verblijf in de politiecel en alternatieven hiervoor - lijken beide landen echter achter te lopen op de waarborgen neergelegd in Richtlijn 2016/800/EU. De maximale termijn in België voor jeugdigen in een politiecel (maximaal 24 uur) valt als positief te bestempelen. Vergeleken met de maximale termijn in Nederland voor jeugdigen in een politiecel - 10 dagen voor jeugdigen boven de 16 jaar en 3 dagen voor jeugdigen onder de 16 jaar - kan voorzichtig worden geconcludeerd dat Nederland op dit gebied een voorbeeld kan nemen aan België. De verplichte consultatiebijstand lijkt in beide landen een belangrijke oorzaak te zijn voor de lange periode van het verblijf van jeugdigen in politiecellen.

In de praktijk lijken België en Nederland anders om te gaan met het toepassen van de voorlopige vrijheidsbenemende maatregel als uiterste redmiddel en voor de kortst mogelijke duur. In België wordt meer gebruikgemaakt van alternatieve wijzen van tenuitvoerlegging via vrijheidsbeperkende maatregelen. In Nederland wordt meer gebruikgemaakt van de schorsing van de tenuitvoerlegging onder voorwaarden. In theorie lijken dit verschillende oplossingen, maar in de praktijk komt het voor de jeugdige op hetzelfde neer: zij moeten zich houden aan voorwaarden en bevinden zich niet in een gesloten inrichting voor jeugdigen. Het is 
lastig om te bepalen in hoeverre Nederland en België in de praktijk gebruikmaken van alternatieven in de eerste fase op het politiebureau. In Nederland is vrij weinig bekend over dergelijke alternatieven en in de praktijk blijken er vele organisatorische belemmeringen te bestaan. In België is het praktijkonderzoek in deze fase nog geringer.

Beide landen lijken voorlopige vrijheidsbenemende maatregelen als uiterste redmiddel en voor de kortst mogelijke duur voorop te stellen. Daarnaast kent de wet verschillende alternatieven voor de tenuitvoerlegging van een mogelijke voorlopige vrijheidsbenemende maatregel. Mijns inziens kan worden geconcludeerd dat de wettelijke regelgeving in beide landen voldoende mogelijkheden biedt om bij de jeugdige geen voorlopige vrijheidsbenemende maatregel regulier op te leggen. Linksom of rechtsom, in de praktijk maakt het vrijwel niet uit of er sprake is van een alternatieve wijze van tenuitvoerlegging of schorsing van de tenuitvoerleggen onder voorwaarden. Er kan niet worden gezegd of de wijze van België met het jeugdbeschermingsrecht beduidend beter werkt dan het jeugdstrafrecht van Nederland. Voor beide varianten zijn argumenten aan te voeren met het oog op het belang van het kind.

Om de regelgeving en de praktijk van Nederland en België te laten voldoen aan de bepalingen van de Richtlijn 2016/800/EU zijn enkele aanbevelingen te maken. Ten aanzien van het maximaal aantal dagen waarop een minderjarige verdachte in een politiecel mag verblijven, dient onderzoek te worden gedaan in hoeverre de Nederlandse regelgeving kan worden aangepast aan de regelgeving in België. Tijdens de beginfase moet voldoende ruimte blijven om onderzoek te doen naar de zaak, maar in het achterhoofd moet worden gehouden dat België meer lijkt aan te sluiten bij de bepaling van de richtlijn om vrijheidsbeneming zo kort te laten duren als passend is, met een maximum van 24 uur. Daarnaast is van belang om te onderzoeken welke alternatieven voor de tenuitvoerlegging van een vrijheidsbenemende maatregel mogelijk en haalbaar zijn in Nederland. Er wordt veelal gebruikgemaakt van schorsing van de voorlopige hechtenis, maar op het gebied van alternatieven blijft het relatief stil. De eerste stappen op het gebied van het ontwikkelen van 'kindvriendelijke' voorlopige vrijheidsbenemende maatregelen zijn gezet. Aan Nederland en België de taak om de Richtlijn 2016/800/EU zo juist en volledig mogelijk te implementeren. 